\title{
Identification of B2-microgloblin as a candidate for early diagnosis of imaging-invisible hepatocellular carcinoma in patient with liver cirrhosis
}

\author{
YUMI SAITO $^{1}$, NOBUYUKI OBA ${ }^{2}$, SYUTA NISHINAKAGAWA ${ }^{2}$, YASUHIRO MIZUGUCHI ${ }^{2}$, \\ TATSUYA KOJIMA $^{2}$, KAZUHIRO NOMURA ${ }^{2}$ and TETSUYA NAKATSURA ${ }^{1}$ \\ ${ }^{1}$ Section for Cancer Immunotherapy, Investigative Treatment Division, Research Cancer for Innovative Oncology, \\ National Cancer Center Hospital East, 6-5-1 Kashiwanoha, Kashiwa, Chiba 277-8577; ${ }^{2}$ Tokyo Rosai Hospital, \\ Department of Internal Gastroenterology, 4-13-21 Omoriminami, Ota-ku, Tokyo 143-0013, Japan
}

Received September 25, 2009; Accepted November 2, 2009

DOI: $10.3892 /$ or_00000767

\begin{abstract}
Glypican-3 (GPC3) is overexpressed in hepatocellular carcinoma $(\mathrm{HCC})$ but not in chronic hepatitis $(\mathrm{CH})$ and liver cirrhosis (LC). We have reported the possibility of GPC3-specific cytotoxic T lymphocytes (CTLs) serving as a marker for the early diagnosis of imaging invisible HCC. In this study, to identify new early diagnostic biomarker of imaging invisible $\mathrm{HCC}$, we analyzed plasma of healthy donors and patients with $\mathrm{CH}, \mathrm{LC}$ and $\mathrm{HCC}$ using surface-enhanced laser desorption-ionaization time-of-flight mass spectrometry (SELDI-TOF-MS). The intensities of four peaks were significantly increased in HCC patients compared with healthy donors. Two of these four peaks were significantly higher in $\mathrm{CH}$ and LC patients with GPC3-specific CTLs than in those without. One peak $(11.7 \mathrm{kDa})$ was predicted to be 32 microglobulin ( $\beta 2-\mathrm{MG})$ by molecular mass. There was a correlation between concentration of $32-\mathrm{MG}$ by latex agglutination immunoassay in plasma and peak intensity using SELDI-TOF-MS. The $11.7 \mathrm{kDa}$ protein was fractionated by gel filtration and was identified as $132-\mathrm{MG}$ by
\end{abstract}

Correspondence to: Dr Tetsuya Nakatsura, Section for Cancer Immunotherapy, Investigative Treatment Division, Research Center for Innovative Oncology, National Cancer Center Hospital East, 6-5-1 Kashiwanoha, Kashiwa 277-8577, Japan

E-mail: tnakatsu@east.ncc.go.jp

Abbreviations: B2-MG, B2-microglobulin; HCC, hepatocellular carcinoma; GPC3, glypican-3; CH, chronic hepatitis; LC, liver cirrhosis; CTLs, cytotoxic T lymphocytes; AFP, $\alpha$-fetoprotein; SELDI-TOF-MS, surface-enhanced laser desorption-ionaization time-of-flight mass spectrometry; LAIA, latex agglutination immunoassay; PIVKA-II, protein induced by vitamin $\mathrm{K}$ absence

Key words: surface-enhanced laser desorption-ionaization time-offlight mass spectrometry, glypican-3, cytotoxic T lymphocyte, chronic hepatitis, liver cirrhosis, hepatocellular carcinoma
Western blot analysis. These results suggest that the level of B2-MG in plasma from patients with $\mathrm{CH}$ and $\mathrm{LC}$ could be a useful marker for the early diagnosis of imaging invisible HCC, however further investigation is needed.

\section{Introduction}

Glypican-3 (GPC3) belongs to glypican family that is a group of heparan sulfate proteoglycans linked to the outer surface of cell membrane through a glycosylphosphatidylinositol anchor (1). GPC3 is overexpressed in hepatocellular carcinoma (HCC) (2) and was a useful diagnostic marker for a component HCC (3). Also, GPC3 is a useful tumor marker in early HCC $(2,4,5)$. We have reported that GPC3 was correlated with poor prognosis in HCC (6). Furthermore, we showed the usefulness of GPC3 as a target for cancer immunotherapy (7-9). We are undertaking a phase I clinical trial of GPC3 peptide vaccine for patients with advanced HCC.

$\mathrm{HCC}$ is one of the most common malignant tumors worldwide (10). Patients with liver cirrhosis (LC) are at higher risk for the development of HCC (11). To date diagnostic imaging such as Computer Tomography (CT) or Magnetic Resonance Imaging (MRI) is taken as the gold standard for definitive diagnosis of HCC. Several serum markers developed for the diagnosis of HCC, including evaluation of $\alpha$-fetoprotein (AFP) and protein induced by vitamin $\mathrm{K}$ absence (PIVKA-II) $(12,13)$. AFP and PIVKA-II is most widely used as a diagnostic serum marker for $\mathrm{HCC}$, however its early diagnostic value is poor $(14,15)$. Thus there are no available tumor markers or means for detecting invisible HCC by CT or MRI.

We have previously reported that anti-GPC3 IgG was detected in the serum of patients not only with $\mathrm{HCC}$ but also with chronic hepatitis $(\mathrm{CH})$ and LC (16). In addition, in the same study, we reported that GPC3-specific cytotoxic T lymphocytes (CTLs) were present in the peripheral blood mononuculear cells (PBMCs) of patients not only with HCC but also with $\mathrm{CH}$ or LC using ex vivo IFN- $\gamma$ enzyme-linked immunospot (ELISPOT) assay. GPC3-specific CTLs should react to the GPC3 expressing HCC cells. The detection of GPC3-specific CTLs shows the existence of GPC3 expressing 
HCC cells in these $\mathrm{CH}$ and LC patients. This suggested that GPC3-specific CTLs could serve as a marker for the early diagnosis of imaging invisible HCC. Therefore, in this study, we tried to identify the HCC producing protein in the serum of $\mathrm{CH}$ and LC patients who were positive for GPC3-specific CTLs.

ProteinChip, based on surface-enhanced laser desorptionionization time-of-flight mass spectrometry (SELDI-TOF-MS) has recently been shown to be useful in discovering biomarkers for the diagnosis of breast, liver and various other cancers (17-21). In order to establish the possibility of early diagnosis of imaging invisible HCC, we analyzed plasma from patients with $\mathrm{CH}$ and LC patients with or without GPC3-specific CTLs and HCC patients using ProteinChip Arrays.

\section{Materials and methods}

Plasma samples. Plasma samples were obtained from 6 patients with $\mathrm{HCC}$ at National Cancer Center Hospital East, 16 patients with $\mathrm{CH}$ or LC at Tokyo Rosai Hospital and 8 healthy volunteers after obtaining their written consent. $\mathrm{CH}$ and $\mathrm{LC}$ patients who were confirmed to be HCV-RNA (+) or HBs antigen $(+)$ within six months prior to registration were eligible for the study. The diagnosis of $\mathrm{CH}$ or LC was made clinically by imaging and laboratory data. The patients had no medical history of HCC and no evidence of HCC on ultrasonography, $\mathrm{CT}$ or MRI conducted prior to registration. All plasma samples were stored at $-80^{\circ} \mathrm{C}$ until analysis.

SELDI-TOF-MS analysis. For SELDI-TOF-MS analysis, we used CM10 ProteinChip (weak cation-exchange) with anionic surface chemistry. The chips were washed twice with shaking for $5 \mathrm{~min}$ in $150 \mu \mathrm{l}$ binding buffer $(50 \mathrm{mM}$ sodium acetate, $\mathrm{pH}$ 4.0) per well. Plasma samples diluted 1:10 with PBS buffer and then diluted 1:10 with $\mathrm{pH}$ adjusted buffer. One hundred microliters of all diluted plasma samples were applied on each ProteinChips. The samples were applied in duplicate. Binding was allowed to proceed for $1 \mathrm{~h}$ with shaking at room temperature. The chips were then washed twice using $150 \mu 1$ of binding buffer ( 5 min with shaking), rinsed, dried and then added $0.5 \mu 1$ of a matrix solution (50\% acetonitrile, $0.5 \%$ trifluoroacetic acid) to each spot. Matrix solution was repeatedly put to each spot. These ProteinChip Arrays were analyzed using a ProteinChip reader (ProteinChip Biology Systems II; Bio-Rad Laboratories, Inc., Tokyo, Japan).

High performance liquid chromatography (HPLC) analysis. Plasma samples were analyzed by the HPLC (Shimadzu, Kyoto, Japan). All samples were fractionated by size-exclusion HPLC chromatography equipped on a shodex protein $\mathrm{KW}$ 802.5 column (Showa Denko, Tokyo, Japan). One hundred microliters of the sample was loaded into the column: a mobile phase composed of A solution $\left(20 \mathrm{mM} \mathrm{NaH}_{2} \mathrm{PO}_{4} \cdot 2 \mathrm{H}_{2} \mathrm{O}\right.$ $300 \mathrm{mM} \mathrm{NaCl}$ ) and B solution $\left(20 \mathrm{mM} \mathrm{NaH} \mathrm{PO}_{4} \cdot 2 \mathrm{H}_{2} \mathrm{O}\right)$; a flow rate of $1.0 \mathrm{ml} / \mathrm{min}$; UV detection at $280 \mathrm{~nm}$. Appropriate fractions were concentrated in Vivaspin 2 column $(3 \mathrm{kDa}$ cut off) (GE Healthcare, UK Ltd.). The search for retention time of B2-MG of purified standard protein (Biocode Hycel, Liege, Belgium), fractionated using the same method for all plasma samples.
Table I. Characteristics of patients involved in this study.

\begin{tabular}{lccc}
\hline & $\begin{array}{c}\text { Male/ } \\
\text { Female }\end{array}$ & $\begin{array}{c}\text { Average } \\
\text { age }\end{array}$ & HBV/HCV \\
\hline $\begin{array}{l}\text { GPC3-specific CTL } \\
\text { Negative patients }\end{array}$ & $5 / 1$ & $60.3(51-75)$ & $1 / 5$ \\
$\begin{array}{l}\text { GPC3-specific CTL } \\
\text { Negative patients }\end{array}$ & $3 / 3$ & $67.7(59-74)$ & $2 / 4$ \\
HCC patients & $2 / 4$ & $66.1(48-77)$ & $2 / 4$ \\
\hline
\end{tabular}

Detection of $\beta 2$-microglobulin $(\beta 2-M G)$ in plasma by latex agglutination immunoassay (LAIA). The concentration of B2-MG in plasma samples was measured using a latex agglutination immunoassay (LAIA) at SRL, Tokyo, Japan. The normal range of healthy donor plasma levels of B2-MG was $0.9-2.0 \mathrm{mg} / \mathrm{l}$.

Western blot analysis. Plasma samples were measured by Bradford protein assay and adjusted to equal concentration for Tris-tricine SDS-polyacrylamide gel electrophoresis (PAGE). The samples in each were separated on $16.5 \%$ gels and transferred to polyvinylidene difluoride (PVDF) membrane (Millipore). The membrane was blocked by $5 \%$ milk powder in TBS-0.5\% Tween-20 buffer (TBS-T) for $1 \mathrm{~h}$ at room temperature and then incubated with mouse anti-32-MG antibody (1:1000, Hokudo, Sapporo, Japan) overnight at $4^{\circ} \mathrm{C}$, followed by reaction with horseradish peroxidase (HRP)conjugated anti-mouse IgG antibody (1:20000, Jackson ImmunoResearch, USA). The signal was developed using ELC plus Western Blotting Detection Reagent (GE Healthcare, $\mathrm{UK})$.

\section{Results}

Selection of the candidate protein for detecting invisible HCC using SELDI-TOF-MS. To search for novel markers for detecting invisible HCC by CT or MRI, we performed proteomic analysis using ProteinChip Array. At first, we compared the protein profiling in the plasma between 6 HCC patients and 6 healthy donors (Table I). We found four peaks $(2.7,11.7,51.7$ and $118.6 \mathrm{kDa})$ to be significantly higher in HCC patients than in healthy donors (Fig. 1). Intensity of the peaks discriminated significantly between HCC patients and healthy donors, $\mathrm{P}=0.01(2.7 \mathrm{kDa}), \mathrm{P}=0.006(11.7 \mathrm{kDa})$, $\mathrm{P}=0.04$ (51.7 kDa), $\mathrm{P}=0.001$ (118.6 kDa).

For further analyses, the protein expression profiles in the plasma between $6 \mathrm{CH}$, LC patients with GPC3-specific CTLs and $6 \mathrm{CH}$, LC patients without GPC3-specific CTLs were compared (Table I, Fig. 2A and B). The intensity of two peaks (11.7 and $51.7 \mathrm{kDa}$ ) were significantly higher than in the plasma of GPC3-specific CTLs positive patients as compared with GPC3-specific CTLs negative patients. A protein peak of 11.7 or $51.7 \mathrm{kDa}$ discriminated significantly between GPC-specific CTLs negative patients and HCC patients $(\mathrm{P}=0.002$ or $\mathrm{P}=0.007)$, as well as between GPC3- 
A

$$
\text { peak }
$$
Intensity $2.7 \mathrm{kDa}$

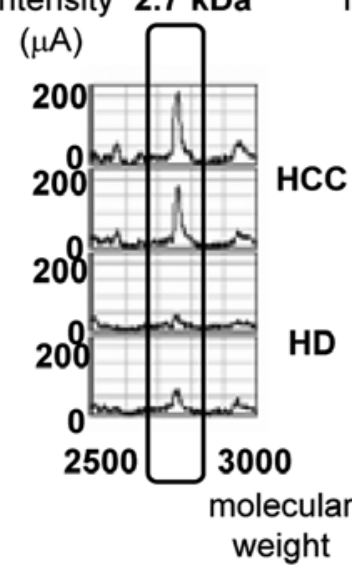

C

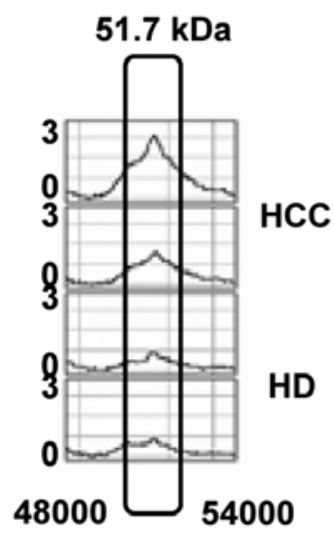

peak

Intensity

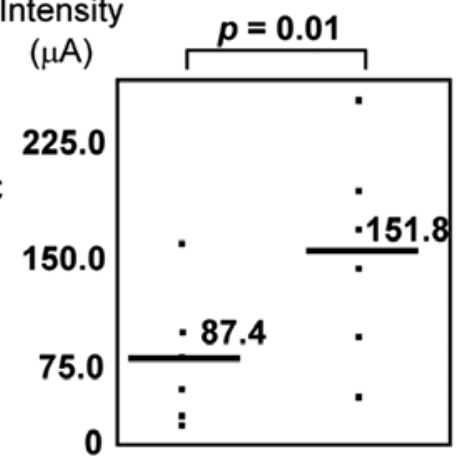

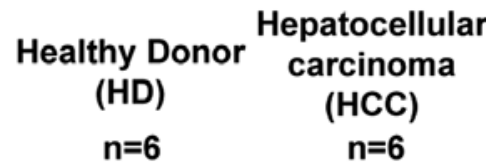

ar

D

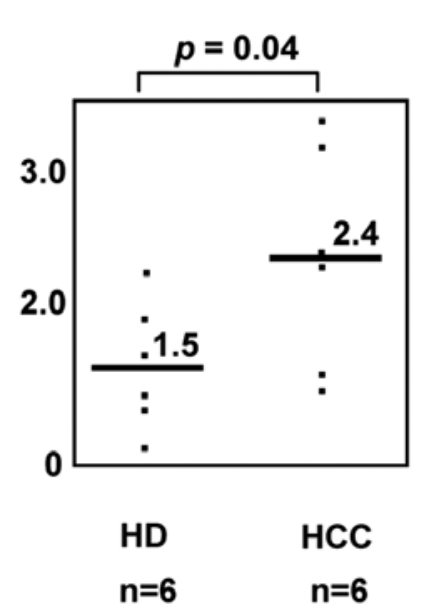

$118.6 \mathrm{kDa}$

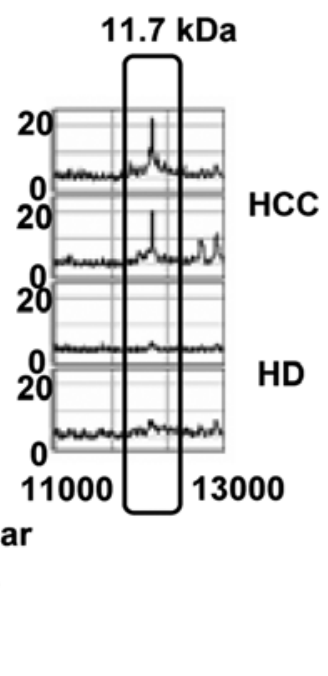

B
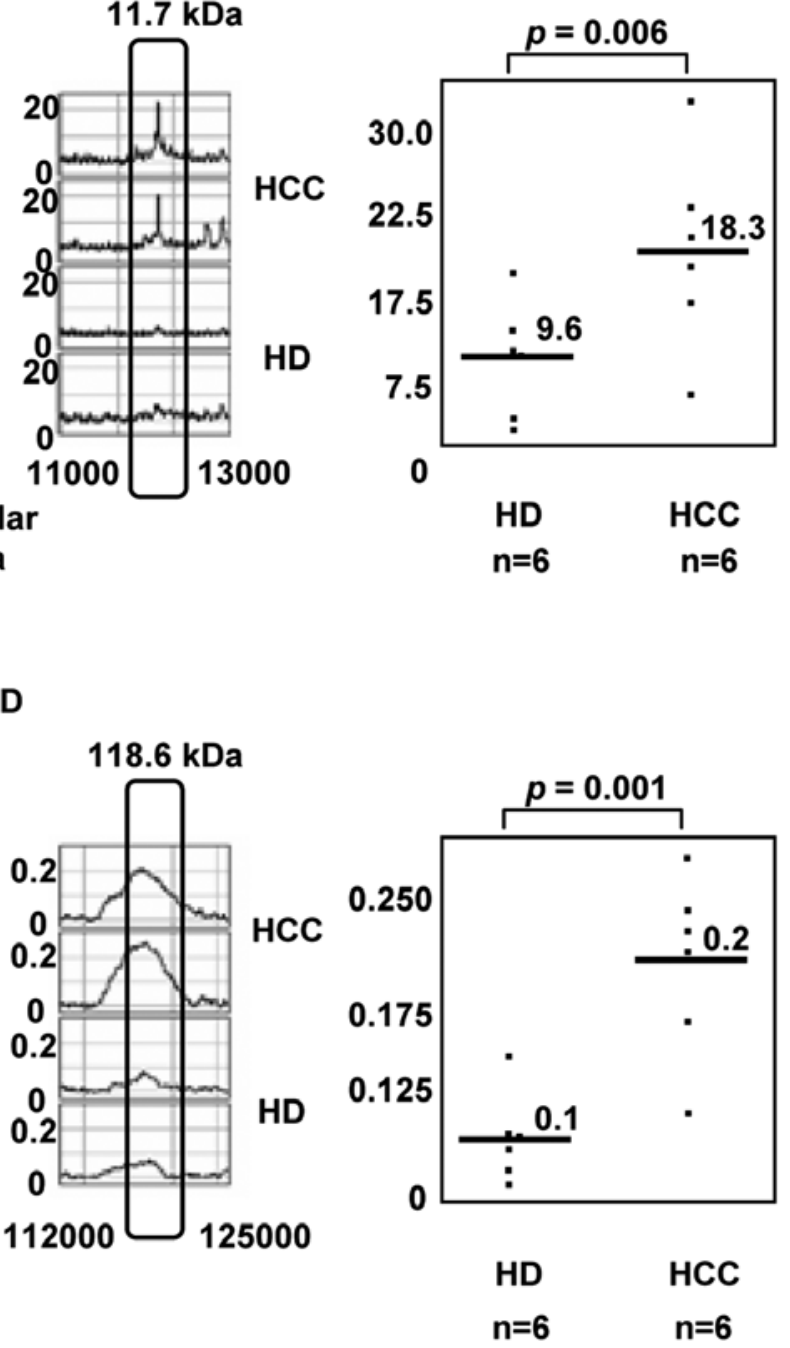

Figure 1. Comparison of the intensity of different expressed peaks in hepatocellular carcinoma (HCC) patients and healthy donors (HD). The spectra were obtained using CM10 ProteinChip (weak cation-exchange) arrays. Distribution of the intensity of different expressed peaks in plasma samples. Distribution of signal intensities for the $2.7 \mathrm{kDa}$ protein $(\mathrm{A})$, the $11.7 \mathrm{kDa}$ protein $(\mathrm{B})$, the $51.7 \mathrm{kDa}$ protein $(\mathrm{C})$ and the $118.6 \mathrm{kDa}$ protein $(\mathrm{D})$ were shown. Black bars indicate mean intensity.

Table II. Search results from SELDI-TOF-MS analysis data using ExPASy Tagldent.

\begin{tabular}{|c|c|c|c|}
\hline Molecular weight & Entry name & Protein name & Accession no. \\
\hline 11731 & B2-MG_HUMAN & B2-microglobulin & P61769 \\
\hline 11684 & NRTN_HUMAN & Neurturin & Q99748 \\
\hline 11710 & KCNE3_HUMAN & Potassium voltage-gated channel subfamily E member 3 & Q9Y6H6 \\
\hline
\end{tabular}

specific CTLs positive patients and HCC $(\mathrm{P}=0.04$ or $\mathrm{P}=0.02)$.

Prediction of $\beta 2$-microgloblin $(\beta 2-M G)$ as a $11740 \mathrm{kDa}$ protein using ExPASy server. To identify the $11740 \mathrm{kDa}$ protein, we used the TagIdent tool from the ExPASy proteomic server (http://www .expasy.ch/tools/tagident.html). By entering the molecular mass unknown protein, this tool will search in the TrEMBL and Swiss-Plot protein database for proteins that will match with the requested molecular mass. From the results of the search from ExPASy Tagldent, we focused on B2-MG. Peak of $11.7 \mathrm{kDa}$ was predicted to be $32-\mathrm{MG}$ by molecular mass (Table II).

Identification of the $\beta 2$-microgloblin $(\beta 2-M G)$. We examined the plasma level of $32-\mathrm{MG}$ in six novel donors (HD-1, 2, CH- 
A

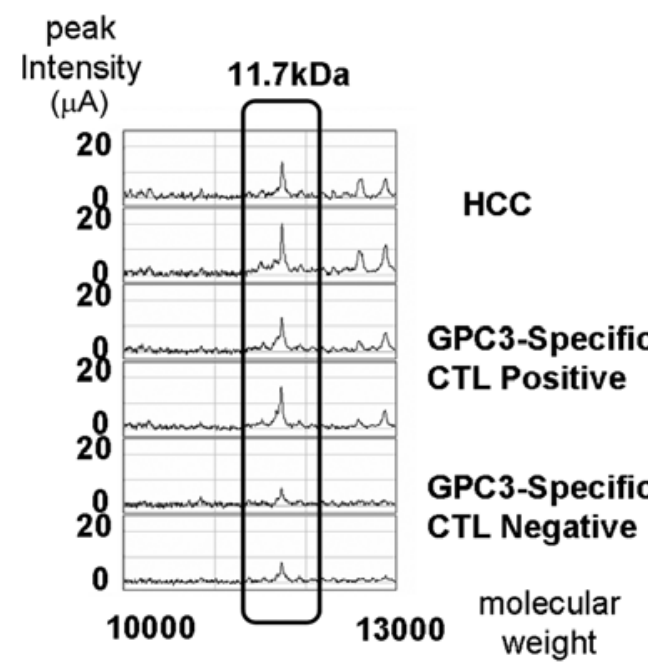

B

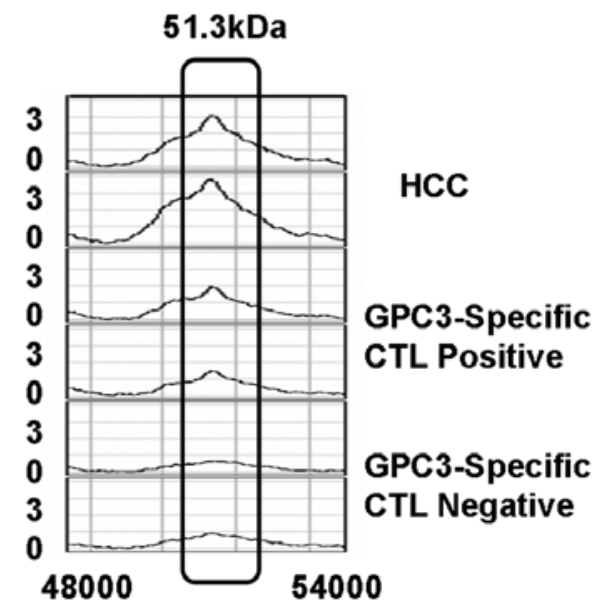

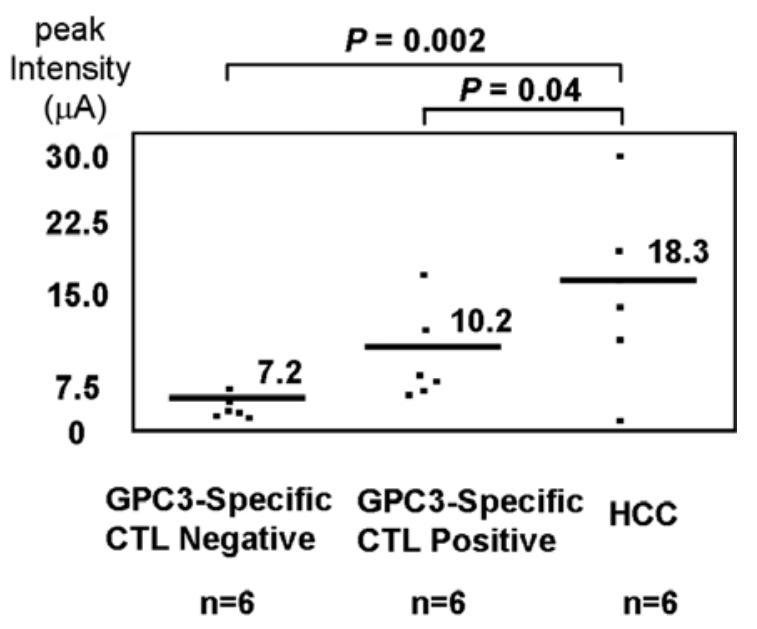

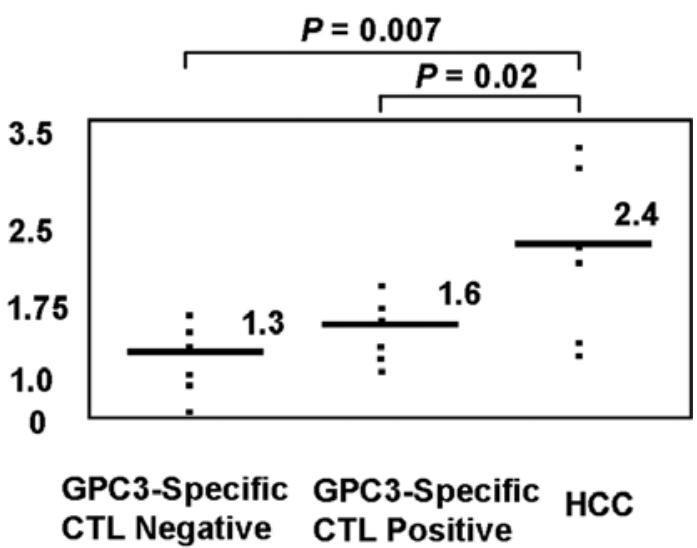

$n=6$

$n=6$

Figure 2. Comparison of the intensity of different expressed peaks in CH/LC patients who are positive for Glypican-3 (GPC3)-specific CTLs. CH/LC patients who are negative and HCC. Data were obtained using CM10 arrays. Distribution of signal intensities for the $11.7 \mathrm{kDa}$ protein (A) and the $51.7 \mathrm{kDa}$ protein (B) are shown.

1, 2 and LC-1,2) by LAIA. To see whether relative peak intensity of $11.7 \mathrm{kDa}$ protein in SELDI-TOF-MS analysis was correlated with plasma $32-\mathrm{MG}$ levels determined by an LAIA or not (Fig. 3). As shown in Fig. 3A and B, there was a positive correlation between the peak intensity and the concentration of $32-\mathrm{MG}$. To further confirm our results, Western blot analysis with mouse anti- $32-\mathrm{MG}$ antibody was performed on the plasma (HD-1, 2, CH-1, 2, LC-1, 2, in Fig. $3 \mathrm{~A})$. As expected, a specific band at $11.7 \mathrm{kDa}$ was clearly detected in plasma samples (Fig. 3C). These results suggest that $11.7 \mathrm{kDa}$ band should be $32-\mathrm{MG}$.

Fractionation of the $11.7 \mathrm{kDa}$ protein peak, $\beta 2-M G$. To confirm $11.7 \mathrm{kDa}$ protein as $32-\mathrm{MG}$, the plasma was fractionated by gel filtration and HPLC. We fractionated 32 -
MG standard using size-exclusion chromatography. The peak eluted for the B2-MG standard at retention time $20.049 \mathrm{~min}$ (Fig. 4A). Fractions were collected at retention times from 15 to $18 \mathrm{~min}$ (Fr. 1), 18 to $24 \mathrm{~min}$ (Fr. 2: the same retention time as the fraction of B2-MG standard), 24 to $31 \mathrm{~min}$ (Fr. 3), 31 to 34 min (Fr. 4) and B2-MG standard (Fig. 4B). Western blot analysis with mouse anti-B2-MG antibody was performed to a set of collected fractions. As expected, only a single specific band at $\sim 12 \mathrm{kDa}$ was detected with unpurified plasma, Fr. 2 and B2-MG standard (Fig. 4C).

\section{Discussion}

SELDI-TOF-MS has been successfully applied in biomarker detection and identification in ovarian, lung, colon and 
A

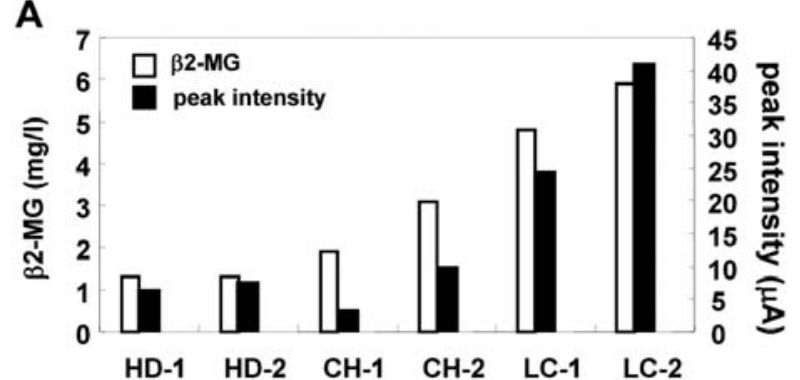

B

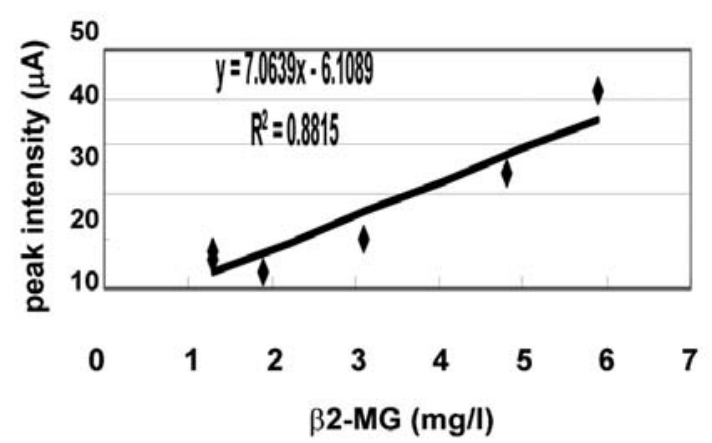

C

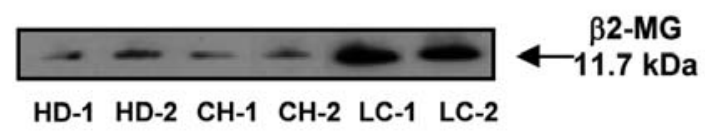

Figure3. Prediction of $11.7 \mathrm{kDa}$ protein peak as $\beta 2$-microglobulin (ß2-MG) (A) Correlation between peak intensity of $11.7 \mathrm{kDa}$ in healthy donors (HD)-1, 2, patients with chronic hepatitis (CH)-1, 2, liver cirrhosis (LC)-1, 2 by SELDI-TOF-MS and concentration of $32-\mathrm{MG}$ by latex agglutination immunoassay (LAIA). (B) Correlation between $11.7 \mathrm{kDa}$ proteins intensity by SELDI-TOF-MS and concentration of B2-MG by LAIA are shown. The values are well correlated. (C) Western blot analysis of B2-MG in two pairs of healthy donors (HD) and patients (CH, LC) plasma. The band of B2-MG is shown with an arrow.

various cancers (22-25). In this study, in order to search for new biomarkers of $\mathrm{CH}$ and $\mathrm{LC}$, we analyzed plasma using ProteinChip Array. We have identified B2-MG as a new biomarker in $\mathrm{CH}$ and $\mathrm{LC}$ patients who have GPC3-specific CTLs.

ß2-MG is a non-glycosylated polypeptide composed of 99 amino acids (26). It is one of the components of major histocompatibility complex HLA class I molecules on the cell surface of all nucleated cells (27). Increased serum levels of $32-\mathrm{MG}$ also occur in a variety of multiple myeloma, lymphoma, Sjögren's syndrome and amyloid fibrils in patients receiving hemodialysis for long periods (28-30). It has been reported that the level of serum $32-\mathrm{MG}$ was elevated in patients with chronic hepatitis $\mathrm{C}, \mathrm{HCV}$-related $\mathrm{HCC}$ when compared to HCV-negative patients or healthy donors $(31,32)$. However, it has not yet been reported that the detection of $32-\mathrm{MG}$ in plasma may show the invisible HCC by CT or MRI and that high $32-\mathrm{MG}$ in the plasma is a risk factor for developing HCC.

The mechanism of the increase of $32-\mathrm{MG}$ in amyloid fibrils in patients receiving hemodialysis for long periods has been elucidated, but previously the relationship between mechanism in $32-\mathrm{MG}$ and risk for the developing of $\mathrm{HCC}$ has not been reported.

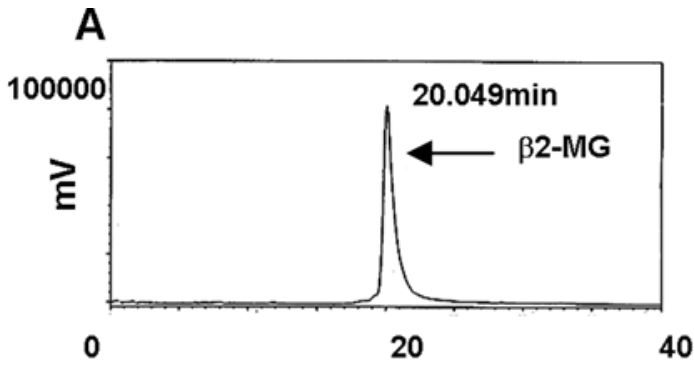

Retention time

B 10500 13000

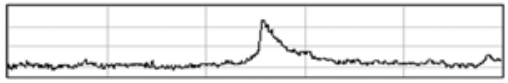

Plasma
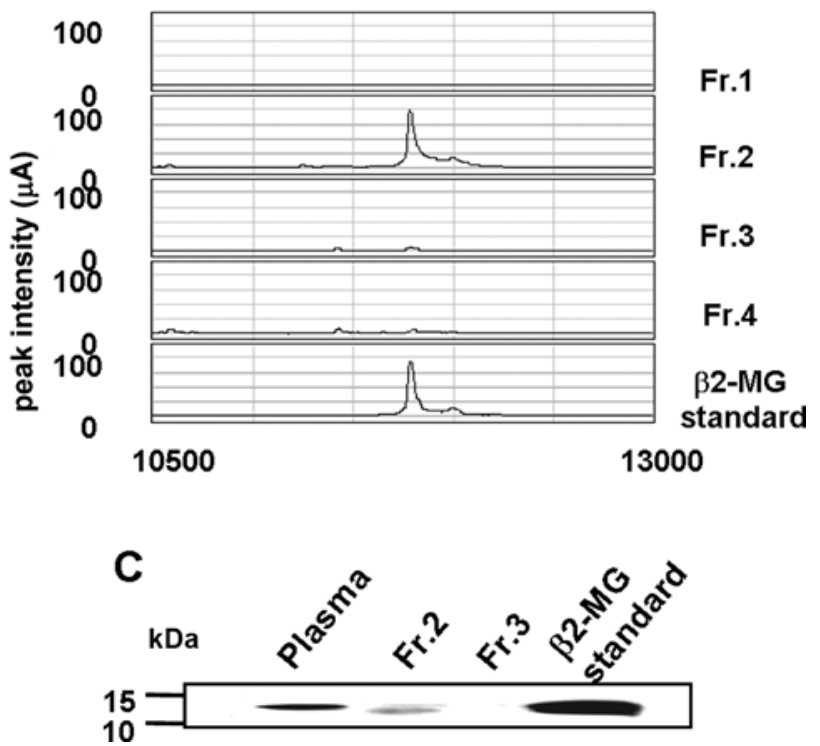

Figure 4. Fractionation of $11.7 \mathrm{kDa}$ protein peak as $32-\mathrm{MG}$. (A) High performance liquid chromatography (HPLC) of B2-MG standard, absorbance at $280 \mathrm{~nm}$. (B) Fractionation of HPLC by SELDI-TOF-MS. (C) Western blot analysis of each fractionation of HPLC and B2-MG standard.

In this study, we showed that $32-\mathrm{MG}$ in plasma increased in $\mathrm{CH}$ and LC patients with GPC3-specific CTLs, and suggested that the $32-\mathrm{MG}$ in plasma could be a marker to detect imaging-invisible HCC. To confirm these results, we will evaluate the correlation between level of $32-\mathrm{MG}$ and risk for developing HCC in a large-scale analysis using many plasma samples of $\mathrm{CH}$ and LC patients. In addition, we aim at identifying a good diagnostic marker for imaging-invisible HCC.

\section{Acknowledgements}

We thank Ms. Kaori Matsuzawa for technical assistance and Ms. Frances Gleeson for assisting in the preparation of this manuscript. This study was supported in part by Health and Labor Science Research Grants for Research on Hepatitis from the Ministry of Health, Labor and Welfare, Japan. 


\section{References}

1. Filmus $\mathrm{J}$ : The contribution of in vivo manipulation of gene expression to the understanding of the function of glypicans. Glycoconj J 19: 319-323, 2002.

2. Nakatsura T, Yoshitake Y, Senju S, et al: Glypican-3, overexpressed specifically in human hepatocellular carcinoma, is a novel tumor marker. Biochem Biophys Res Commun 306: $16-25,2003$

3. Shirakawa H, Kuronuma T, Nishimura Y, et al: Glypican-3 is a useful diagnostic marker for a component of hepatocellular carcinoma in human liver cancer. Int J Oncol 34: 649-656, 2009.

4. Hippo Y, Watanabe K, Watanabe A, et al: Identification of soluble NH2-terminal fragment of glypican-3 as a serological marker for early-stage hepatocellular carcinoma. Cancer Res 64: 2418-2423, 2004.

5. Nakatsura T and Nishimura Y: Usefulness of the novel oncofetal antigen glypican-3 for diagnosis of hepatocellular carcinoma and melanoma. BioDrugs 19: 71-77, 2005.

6. Shirakawa H, Suzuki H, Shimomura M, et al: Glypican-3 expression is correlated with poor prognosis in hepatocellular carcinoma. Cancer Sci 100: 1403-1407, 2009.

7. Nakatsura T, Komori H, Kubo T, et al: Mouse homologue of a novel human oncofetal antigen, glypican-3, evokes T-cellmediated tumor rejection without autoimmune reactions in mice. Clin Cancer Res 10: 8630-8640, 2004.

8. Motomura Y, Senju S, Nakatsura T, et al: Embryonic stem cellderived dendritic cells expressing glypican-3, a recently identified oncofetal antigen, induce protective immunity against highly metastatic mouse melanoma, B16-F10. Cancer Res 66: 2414-2422, 2006.

9. Motomura Y, Ikuta Y, Kuronuma T, et al: HLA-A2 and -A24restricted glypican-3-derived peptide vaccine induces specific CTLs: preclinical study using mice. Int J Oncol 32: 985-990, 2008.

10. Parkin DM, Bray F, Ferlay J and Pisani P: Estimating the world cancer burden: Globocan 2000. Int J Cancer 94: 153-156, 2001.

11. Schafer DF and Sorrell MF: Hepatocellular carcinoma. Lancet 353: 1253-1257, 1999.

12. Williams R, Melia WM and Johnson PJ: Serum alphafoetoprotein in hepatocellular carcinoma-value in diagnosis, and prognosis. Ann Acad Med Singapore 9: 245-250, 1980.

13. Fujiyama S, Morishita T, Sagara K, Sato T, Motohara K and Matsuda I: Clinical evaluation of plasma abnormal prothrombin (PIVKA-II) in patients with hepatocellular carcinoma. Hepatogastroenterology 33: 201-205, 1986.

14. Suehiro T, Sugimachi K, Matsumata T, Itasaka H, Taketomi A and Maeda T: Protein induced by vitamin K absence or antagonist II as a prognostic marker in hepatocellular carcinoma. Comparison with alpha-fetoprotein. Cancer 73: 2464-2471, 1994.

15. Sherman M: Alpha-fetoprotein: an obituary. J Hepatol 34: 603$605,2001$.

16. Hayashi E, Motomura Y, Shirakawa H, et al: Detection of glypican-3-specific CTLs in chronic hepatitis and liver cirrhosis. Oncol Rep 22: 149-154, 2009.
17. Li J, Zhao J, Yu X, et al: Identification of biomarkers for breast cancer in nipple aspiration and ductal lavage fluid. Clin Cancer Res 11: 8312-8320, 2005.

18. Zinkin NT, Grall F, Bhaskar K, et al: Serum proteomics and biomarkers in hepatocellular carcinoma and chronic liver disease. Clin Cancer Res 14: 470-477, 2008.

19. Ishida Y, Yamashita K, Sasaki H, et al: Activation of complement system in adult T-cell leukemia (ATL) occurs mainly through lectin pathway: a serum proteomic approach using mass spectrometry. Cancer Lett 271: 167-177, 2008.

20. Liu L, Wang J, Liu B, et al: Serum levels of variants of transthyretin down-regulation in cholangiocarcinoma. J Cell Biochem 104: 745-755, 2008

21. Navaglia F, Fogar P, Basso D, et al: Pancreatic cancer biomarkers discovery by surface-enhanced laser desorption and ionization time-of-flight mass spectrometry. Clin Chem Lab Med 47: 713-723, 2009.

22. Kozak KR, Su F, Whitelegge JP, Faull K, Reddy S and Farias-Eisner R: Characterization of serum biomarkers for detection of early stage ovarian cancer. Proteomics 5: 4589-4596, 2005.

23. Ward DG, Suggett N, Cheng Y, et al: Identification of serum biomarkers for colon cancer by proteomic analysis. Br J Cancer 94: 1898-1905, 2006

24. Ueda K, Fukase Y, Katagiri T, et al: Targeted serum glycoproteomics for the discovery of lung cancer-associated glycosylation disorders using lectin-coupled ProteinChip arrays. Proteomics 9: 2182-2192, 2009.

25. Hegedus CM, Gunn L, Skibola CF, et al: Proteomic analysis of childhood leukemia. Leukemia 19: 1713-1718, 2005.

26. Berggard I and Bearn AG: Isolation and properties of a low molecular weight beta-2-globulin occurring in human biological fluids. J Biol Chem 243: 4095-4103, 1968.

27. Bjorkman PJ, Saper MA, Samraoui B, Bennett WS, Strominger JL and Wiley DC: Structure of the human class I histocompatibility antigen, HLA-A2. Nature 329: 506-512, 1987.

28. Bataille R, Grenier J and Sany J: Beta-2-microglobulin in myeloma: optimal use for staging, prognosis, and treatment - a prospective study of 160 patients. Blood 63: 468-476, 1984.

29. Ryu OH, Atkinson JC, Hoehn GT, Illei GG and Hart TC: Identification of parotid salivary biomarkers in Sjogren's syndrome by surface-enhanced laser desorption/ionization timeof-flight mass spectrometry and two-dimensional difference gel electrophoresis. Rheumatology 45: 1077-1086, 2006.

30. Hagberg H, Killander A and Simonsson B: Serum beta 2microglobulin in malignant lymphoma. Cancer 51: 2220-2225, 1983.

31. Malaguarnera M, Restuccia S, Di Fazio I, Zoccolo AM, Trovato BA and Pistone G: Serum beta2-microglobulin in chronic hepatitis C. Dig Dis Sci 42: 762-766, 1997.

32. Elgendy SM, Hessien M, Elsherbiny MM, Abd El-Salam IM, El-Attar IA and El-Asser Ael B: A panel of molecular markers in hepatitis $\mathrm{C}$ virus-related hepatocellular carcinoma. J Egypt Natl Cancer Inst 17: 270-278, 2005. 